Lastly, througlt the obscurity of language of $\mathrm{Mr}$. Brown's last conclusion, and its several grammatical inaccuracies. it is difficult to descry precisely what he does mean; but we believe that it is this; from the whole of the preceding facts (assertions) it is ascertained that the anti-variolous power of the vaccine is entirely lost in twenty years-that three-fourths of the vaccinated poor will be found to have undergone small-pox before they reach the age of ten or twelve years, and that of the higher classes, though the number be less, yet it is rapidly increasing, " and a more severe, dangerous, and fatal attack of smallpox are (is) found to be the consequence;"' so that the only good resulting from vaccination is to give the semblance of a false security, and to increase the severity and fatality of small-pox !

Really, this is too much; and yet these are the words of the author, who must surely have calculated largely upon the credulity or the ignorance of his readers, before he could have ventured to put forth a conclusion so utterly at variance with experience, so perfectly unfounded, so thoroughly extravagant and irrational.

I and my father have been zealous gratuitous vaccinators for more than thirty years; we have, therefore vaccinated a great many poor, as well as our own private patients. Of these we have records of about twenty failures in somewhat more than 5,000 cases; all of those failures were succeeded by a mild form of modified small-pox, without one death, and this notwithstanding the exasperation of small-pox by vac. cination!!

I might refer to other facts, but I prefer giving my own experience, to set against the experience of $\mathrm{Mr}$. Brown; and with this fact I take my leave of the subject till next week.

$1 \mathrm{am}$, faithfully yours, W. NewnhaM.

\section{STATISTICS OF AMPUTATIONS}

\section{PERFORMED IN}

\section{THE PARISIA N HOSPITALS.}

By M. Malgaigne.

The number of amputations reported to the committee of hospitals, as having been performed in the Parisian hospitals, from the lst of January, 1836, to the 1st of January, 1841, amounted to 852. Of these were, one amputation at the hip-joint; 201 of the thigh; 3 at the knee-joint; 192 of the leg; 38 , partial, of the foot; 8 of the metatarsal bones; 85 of toes. Total 528, of the lower extremity.

For the upper extremity-14 at the shoulder-joint; 91 of the arm; 28 of the forearm; 16 at the wrist joint; 9 of the metacarpal bones; 166 of the fingers. Total, 324.

The general mortality was 332 , or about 2 in 5 viz., 255 for the lower extremity, or nearly one-half; 77 , or about one-fourth, for the upper extremity.

\section{Amputation of Thigh.}

One amputation at the hip-joint in a medical student, aged 21, who had been wounded in a duel.

Of the 201 amputations of the thigh, 126 were followed by death, or nearly 62 per cent. It is neces- sary, however, to distinguish between operations consequent on injuries and those performed for chronic disease.

$a$. Of the first class, $46 ; 34$ deaths; 12 cures.

$b$. Of the second class, $153 ; 92$ deaths to 61 cures, or three deaths out of every five operations.

In addition to these were two amputations, performed successively, by M. Velpeau, on a youngman, for anchylosis of both knees, who recovered.

Ages.-Amputations after Injuries.-From 4 to 15 years, 4 cases, 4 deaths ; from 15 to 35 years, 26 cases, 18 deaths; from 35 to 70 years, 16 cases, 12 deaths.

Amputations after chronic disease.-From 5 to 15 years, 24 cases, 8 deaths; 15 to 35 years, 90 cases, 52 deaths; 35 to 70 years, 39 cases, 32 deaths.

From the above it would appear that operations on persons of tender age are by no means so free from danger as has been supposed.

\section{Amputation at the Knee-joint.}

This operation had been almost completely aban. doned, when it was revived in $1830^{\circ}$, by $M$. Velpeau. The results were so unfavourable that it has again fallen into disuse. Of 9 cases, 7 proved fatal.

$$
\text { 3. Amputation of Leg. }
$$

The number of cases amounted to 192; of these 106 died, about 55 per cent. Of the whole number, 112 were performed in consequence of disease; and gave a mortatity of 55 ; 79 after injuries, with a mortality of 50 .

Finally, one young man, affected with club-foot, was operated on at the Hotel-Dieu, and died. Here, also, as in the former cases, the mortality amongst young subjects was very great in cases of amputations after injuries; it amounted to 3 out of 4 .

\section{Partial Amputation of Foot.}

This was performed in 38 cases, either after Cho. part's method, or between the tarsus and metatarsus. The mortality was 9 in 38 , or 24 per cent.; but here the difference of mortality between operations after injuries and after disease was most striking; in the former case being 6 out of 9 ; in the latter 3 out of 29 cases.

\section{Amputation at the Shoulder-joint.}

The danger of this operation has been variously estimated by different surgeons. M. Larrey says that it succeeded in his hands 90 times out of 100 ; and Percy affirms that of 70 cases about one-sixth proved fatal.

Civil practice furnishes far different results. Of the 13 cases 10 proved fatal; in 7 the operation was per. formed in consequence of injuries, and all died; in 6 , for organic disease, and 5 of these recovered.

\section{Amputation of Arm.}

In 91 cases, 41 deaths, or about 45 per cent. For organic disease 61 operations, 24 deaths ; for injuries 30,17 deaths.

\section{Amputation of Fore.arm.}

In 28 cases 8 deaths, or 28 per cent. For organic disease 17 cases, 5 deaths; for injuries 11 cases, 3 deaths.

\section{Amputation of Wrist-joint.}

During five years amputation was performed at this joint in $\mathbf{1 6}$ cases, and all the patients recovered.

9. Amputation of Metatarsal and Metacarpal Bones.

In 8 cases some one of the metatarsal bones was am. 
putated, and 1 death occurred; in 9 cases one of the metacarpal bones, and here also 1 death occurred.

10. Amputation of Toes.

The great toe was disarticulated in 43 cases, of which 7 proved fatal. The operation was performed in 29 cases for disease, in 14 for injuries; of the former 3 proved fatal, of the latter 4 . The small toe was removed in 26 cases, with 1 fatal result. In 7 cases, where two of the toes were removed together, there was 1 death. Amputation of one or more phalanges was performed in 9 cases, without any accident.

11. Amputation of Fingers.

I have not found it mentioned in any treatise on operative surgery that amputation of the thumb is peculiarly dangerous. It was performed in 9 cases; in 1 for a supernumerary thumb; in 3 for organic disease; in 5 after injury; of the latter 5 no less than 3 proved fatal. The number of cases of amputation of a finger amounted to 119 , amongst which were 10 deaths. In 79 cases the operation was performed in consequence of organic disease; here the mortality was 6 . In 40 cases it was performed after injuries, with 4 deaths.

In 13 cases several fingers at a time were amputated; only 1 case proved fatal. Finally, one of the phalanges was remuved in 24 cases, of which 1 ended in death.

To be continued.

\section{R E V I E W.}

Chemistry in its application to Agriculture and Phy. siology. By Justus Liebig, Ph. D. Second Edition. Edited by Lyon Playfair, Ph. D. London: Taylor and Walton, 1842. 8vo, pp.410.

Although the subjects treated in this original and highly interesting volume may seem to bear but slight relation to the science or practice of medicine, we cannot avoid directing to it the attention of our readers.

Perfect agriculture, as the author remarks, is the true foundation of all trade and industry-it is the foundation of the riches of states. But a rational system of agriculture cannot be formed without the application of scientific principles, for such a system must be based on an exact acquaintance with the means of nutrition of regetables, and with the influ. ence of soils and action of manure on them. This knowledge we derive from chemistry, and the volume which now lies before us contains the results of Liebig's researches in its pursuit.

Professor Liebig's work is divided into two parts; in the first he explains the chemical processes which take place during the nutrition of vegetables; in the second, the chemical processes which occur during fermentation, decay, and putrefaction. The chemical history of the life and death of the vegetable kingdom is thus placed before us in all its details. In the following articles we shall endeavour to furnish a succinct analysis of this history, which is replete with matter of high interest to the physiologist and of utility to the public.

\section{Constituent Elements of Plants.}

The ultimate constituents of plants are those which form organic matter in general-namely, carbon, hydrogen, nitrogen, and oxygen. Carbon is familiarly known as charcoal; hydrogen contributes to form the watery parts of plants; the phenomena of decay depend on its affinity for oxygen, and many of the processes of nutrition originate in an attempt to gratify this affinity.

Nitrogen has little affinity for other bodies, from which it escapes under the influence of very slight forces. Hence, after the death of a plant, it materially assists in promoting decay, by escaping from the compounds of which it formed a constituent. Finally, oxygen is a gaseous substance, possessing a most extensive range of affinities, and contributing mainly to the phenomena of combustion and decay. These four elementary bodies, variously combined, or united with inorganic bases, constitute plants; hence the development of a plant requires the presence, first, of substances containing carbon and nitrogen; secondly, of water and its elements (oxygen and hydrogen), and lastly, of a soil to furnish the inorganic matters which are likewise essential to vegetable life.

Having proceeded thus far, the first question which naturally presents itself is, whence do plants obtain their different organic constituents-carbon, hydrogen, nitrogen, and oxygen? We shall examine these different points in succession.

\section{Assimilation of Carbon.}

Liebig demonstrates, by a series of arguments which we need not repeat, that humus or vegetable mould, manure, \&c., do not serve for the production of carbon and have no influence on it, because the quantity of carbon produced by manured lands is not greater than that yielded by lands which are not manured. Whence, then, do vegetables obtain their carbon, if not from the soil ? The answer is, from the atmosphere, and the carbon contained in the atmosphere exists there in the form of carbonic acid.

These two latter points involve the consideration of two most remarkable natural phenomena, which by their reciprocal and uninterrupted influence maintain the life of the individual animals and regetables, and the continued existence of both kingdoms of organic nature.

The composition of the atmosphere, which surrounds this globe, has been found to be the same at every period of time and in every climate of the world; it has remained unchanged during the lapse of centuries and is unaffected by locality; one hundred volumes of air invariably contain twenty-one volumes of oxygen. On the other hand, large quantities of oxygen are daily abstracted from the atmosphere, while immense masses of carbonic acid flow annually into it. How, then, is the equilibrium kept up ?-how does the composition of the atmosphere constantly remain the same? By the influence of the regetable kingdom. Plants decompose the carbonic acid of the atmosphere, appropriating the carbon for the formation of their principal constituent substances, and restoring the oxygen to the atmosphere for its purification.

"This remarkable property of plants has been demonstrated in the most certain manner, and it is in the power of every person to convince himself of its existence. The leaves and other green parts of a plant absorb carbonic acid, and emit an equal volume 